\title{
Clinicopathological characteristics and survival outcomes of bladder neuroendocrine carcinomas: a population-based study
}

This article was published in the following Dove Press journal: Cancer Management and Research

\author{
Quan Niu, ${ }^{1, *}$ Youyi Lu, ${ }^{2, *}$ \\ Shigao Xu, ${ }^{3}$ Qun Shi, ${ }^{3}$ \\ Baoyu Guo,' Zhe Guo,' \\ Tianbao Huang, ${ }^{3}$ Yinxia $\mathrm{Wu},{ }^{4}$ \\ Junjie $\mathrm{Yu}^{3}$ \\ 'Department of Dalian Medical \\ University, Dalian, Liaoning, People's \\ Republic of China; ${ }^{2}$ Department \\ of Urology, The Affiliated Yantai \\ Yuhuangding Hospital of Qingdao \\ University, Yantai, Shandong, People's \\ Republic of China; ${ }^{3}$ Department of \\ Urology, Subei People's Hospital of \\ Jiangsu Province (Clinical Medical \\ College, Yangzhou University), \\ Yangzhou, Jiangsu, People's Republic \\ of China; ${ }^{4}$ Department of Oncology, \\ Subei People's Hospital of Jiangsu \\ Province (Clinical Medical College, \\ Yangzhou University), Yangzhou, \\ Jiangsu, People's Republic of China \\ *These authors contributed equally to \\ this work
}

Correspondence: Junjie Yu Department of Urology, Subei People's Hospital of Jiangsu Province (Clinical Medical College, Yangzhou University), No 98, Nantong West Road, Yangzhou, jiangsu, People's Republic of China

Tel +86 I 53803 I 5902

Fax +86 05 I48 7373012

Email urologistyji@163.com

Yinxia Wu

Department of Oncology, Subei People's Hospital of Jiangsu Province (Clinical Medical College, Yangzhou University), No 98, Nantong West Road, Yangzhou, Jiangsu, People's Republic of China

Tel +86 I 805 I06 03 I2

Fax +86 05 I48 7373012

Email wuyinxia5I6@I26.com
Background: Bladder neuroendocrine carcinomas (BNECs) are relatively a rare type of tumor. The aim of this study was to examine the clinicopathological characteristics and predictors of survival outcomes of patients with BNECs based on the analysis of the national Surveillance, Epidemiology, and End Results (SEER) database.

Materials and methods: Kaplan-Meier analysis with log-rank test was used for survival comparisons. Multivariate Cox regression model was employed to analyze the effect of different treatments on overall survival (OS) and cancer-specific survival (CSS).

Results: A total of 910 patients were identified between 2004 and 2014. Overall, 648 (71.2\%) patients had small cell neuroendocrine carcinoma (SCNEC), 35 (3.8\%) had large cell neuroendocrine carcinoma (LCNEC), 10 (1.1\%) had carcinoid tumor (well-differentiated neuroendocrine tumor), 16 (1.8\%) had paraganglioma/pheochromocytoma (PGL/PHEO), 619 (68.0\%) had a poorly differentiated or undifferentiated histology grade, 214 (23.5\%) presented with metastatic disease, 586 (64.4\%) underwent transurethral ablation/destruction for bladder tumor, and 245 (26.9\%) had partial/total cystectomy. Cystectomy+chemotherapy+radiotherapy (CCR) has the highest long-term survival rate among various treatments. The 1-, 3-, and 5-years CSS of CCR were $56 \%, 56 \%$, and $56 \%$, respectively. By using multivariable Cox proportional hazard model, age, histology, N stage, SEER stage, tumor size, radiotherapy, chemotherapy, and local treatment of the primary site were identified as independent predictors for OS and CSS; all $P<0.05$. Conclusion: In BNEC, SCNEC has an absolute advantage in number. SCNEC/LCNEC tend to be older men. PGL/PHEO and carcinoid tumors have younger mean ages, earlier tumor stages, and better prognosis than SCNEC/LCNEC. Surgery, radiotherapy and chemotherapy are better than conservative treatment. However, whatever cystectomy or bladder sparing, chemotherapy should be a major component of treatment.

Keywords: bladder neuroendocrine carcinomas, clinicopathological characteristics, prognosis, treatment, Surveillance, Epidemiology, and End Results

\section{Introduction}

Urinary bladder cancer (BCa) with over 79,000 new cases and over 16,000 deaths per year was reported in USA. The morbidity and mortality of $\mathrm{BCa}$ in the male patients were the second highest among all urinary tumors, just after prostate cancer. ${ }^{1}$ Primary bladder neuroendocrine carcinoma (BNEC) is a rare variation of non-urothelial carcinoma of the urinary bladder, representing $<1 \%$ of urinary bladder neoplasms, and is a rare but heterogeneous disease. The 2016 WHO classification of tumors of bladder includes small cell neuroendocrine carcinoma (SCNEC), large cell neuroendocrine carcinoma (LCNEC), paraganglioma (PGL), and well-differentiated neuroendocrine 
tumor. ${ }^{2}$ The major subtype is SCNEC, which displays a particularly dismal prognosis. ${ }^{3}$ There are few published articles of LCNEC, because it is the new subtype of BNEC. ${ }^{4}$ Hematuria and irritative voiding symptoms are the most common presenting clinical signs of four subtype cancers. ${ }^{4-7}$ Diagnosis methods include transurethral biopsy or resection of the lesion. Some tumors even need primary morphology characterization and immunohistochemical stains. ${ }^{8}$

Due to the rarity of BNEC, its biological and clinicopathological characteristics remain largely elusive, precluding the development and evaluation of rational therapeutic strategies. Current knowledge of this disease is limited and is based mainly on small series and case reports. There is no current consensus on standard of treatment programs for patients suffering from this aggressive malignancy. Based on a large cohort of patients, the purpose of this study was to investigate the clinicopathological characteristics and survival outcomes of BNEC. We also analyzed the effect of local surgery of the primary site, chemotherapy, and radiotherapy on BNEC in the hope of offering reliable evidence for the management of BNEC.

\section{Materials and methods}

\section{Study population}

Patients diagnosed with BCa from 2004 to 2014 were identified in the Surveillance, Epidemiology, and End Results (SEER) database. The current SEER database consists of 17 population-based cancer registries and reports cancer-specific outcomes from specific geographic areas representing 28\% of the US population. Patients with BNEC were identified utilizing the primary site codes C67.0 to C67.9 and ICD for oncology, ICD-O-3, codes 8013/3: LCNEC; 8041/3: small cell carcinoma (SCNEC); 8240/3: carcinoid tumor (welldifferentiated neuroendocrine tumor); 8246/3: neuroendocrine carcinoma, not otherwise specified (NOS); 8680/3: paraganglioma; and 8700/3: PGL (PHEO) for a study cohort of 910 patients. Inclusion criterias were as follows: $\mathrm{BCa}$ as the primary cancer diagnosis; complete dates of survival months are available; active follow-up; and patients with more than 0 day of survival. We excluded patients without clear description about the first tumor.

\section{Covariates and follow-up information}

Covariates of interest extracted for each case included patients' social demographic characteristics (ie, age, gender, race, and marital status), tumor grade and stage at the time of diagnosis, histology, tumor size, site of tumor, chemotherapy and radiotherapy, surgery of the primary cancer and metastases. The TNM stage at presentation (only for patients diagnosed starting from 2004 to avoid confusion between different editions of the TNM system). The SEER summary stage (only for patients diagnosed from 1998 to avoid confusion with the historical SEER summary stage) classifies patients as having in situ disease (noninvasive cancer), localized disease (confined to the organ of origin without extension beyond the primary organ), regional disease (direct extension to adjacent organs or structures or by spread to regional lymph nodes), or distant disease (spread to parts of the body remote from the primary tumor). The WHO's standard grading system was used with four separate categories (well, moderately well, poorly differentiated, and undifferentiated). According to the tumor location, patients were subgrouped into trigone, dome, lateral wall, anterior wall, posterior wall, bladder neck, ureteric orifice, urachus, overlapping subsites (overlapping lesion of bladder), bladder, and NOS. Details of local treatment of the primary tumor have also been described including none, local tumor ablation/destruction, and partial/total cystectomy. The primary end points of the study were overall survival (OS) and cancer-specific survival (CSS).

\section{Statistical analysis}

For the estimation of CSS, only death attributable to the BNEC was considered to be an event. Chi-squared test was used to compare the patient characteristics between subtypes. Venn diagram was drawn to illustrate the distribution of main treatments in patients. Survival curves were estimated by the Kaplan-Meier method. The log-rank test and Breslow test were used to assess significant differences for OS and CSS. Multivariate Cox proportional hazard models were constructed to identify the prognostic factors, and HRs and 95\% CI were calculated. Two-sided $P$-values $<0.05$ were considered statistically significant. Venn diagram was drawn by Venny2.1 (http://bioinfogp.cnb.csic.es/tools/venny/index. html). Statistical analysis was performed using the SPSS version 25.0 software package (IBM Corporation, Armonk, NY, USA).

\section{Compliance with ethical standards}

All procedures performed in studies involving human participants were in accordance with the ethical standards of the institutional and national research committee and the 1964 Declaration of Helsinki and its later amendments or comparable ethical standards. This study was partly based on the publicly available data (the SEER database), and we have got the permission to access them for the purpose of 
research only (reference number: 10278-Nov2016). It did not include interaction with humans or use personal identifying information. Thus, the informed consent for this study was not required.

\section{Results}

\section{Patient and tumor characteristics}

According to the inclusion and exclusion criteria, a total of 910 patients with BNEC were identified from 2004 to 2014 and included in our analysis. The characteristics of all patients are presented in Table 1. Among the 709 patients identified in SEER who have clear tumor type, 648 (71.2\%) had SCNEC of the urinary bladder, 35 (3.8\%) had LCNEC of the urinary bladder, $10(1.1 \%)$ had carcinoid tumors of the urinary bladder, and $16(1.8 \%)$ had PGL/PHEO of the urinary bladder. The median age of all patients was 71 years, and all patients are older than 18 years. The male-tofemale ratio was 2.9:1.0. The majority of the cohort (88.7\%) was ethnically white, and 675 (74.2\%) patients were male patients. More than half of the patients are married. In the case of the tumor stage and grade, 694 (76.3\%) patients were suffering from muscle-invasive bladder cancer (MIBC) and only $6(0.7 \%)$ patients had well/moderately differentiated tumor. The most common location of BNEC was on the lateral wall of the bladder 170 (18.7\%), with locations on the trigone, dome, anterior wall, posterior wall, bladder neck, ureteric orifice, and urachus of the bladder being less common. There were 649 (71.3\%) node -negative patients and 647 (71.1\%) M0 (non-transferable) patients. Of 564 patients, tumor sizes $\leq 2 \mathrm{~cm}$ was 66 (7.3\%), $2-5 \mathrm{~cm}$ was 298 $(32.7 \%)$, and $>5 \mathrm{~cm}$ was $200(22.0 \%)$.

\section{Treatment}

The distribution of different treatments is summarized in Table 1, and we applied Venn diagram (Figure 1) to further illustrate the distribution of main treatments. Cancer-directed surgery was performed in 836 (91.9\%) patients. The Venn diagram shows the number of patients with four main kinds of treatments. It shows that $586(64.4 \%)$ underwent transurethral ablation/resection for bladder tumor, 245 (26.9\%) had partial/radical cystectomy, 227 (24.9\%) patients received radiation therapy, and 521 (57.3\%) patients received chemotherapy. Among patients who underwent transurethral ablation/resection, 169 patients underwent adjuvant chemotherapy, 38 patients underwent adjuvant radiotherapy, and 158 patients underwent both adjuvant chemotherapy and adjuvant radiotherapy. Among patients who underwent cystectomy, 147 patients underwent adjuvant chemotherapy, three patients underwent adjuvant radiotherapy, 13 patients underwent adjuvant both therapy. The overlapping area of the Venn diagram represents patients who underwent multiple treatments.

\section{Survival}

The OS and CSS were compared according to different histological types. Kaplan-Meier analyses showed that SCNEC and LCNEC patients had worse outcomes for both OS and CSS compared to carcinoid and PGL/PHEO patients (Figure 2A and B). Kaplan-Meier analyses showed overall survival and cancer-specific survival according to age, tumor size, and SEER stage of bladder neuroendocrine carcinomas (Figure 3A-F). Patients who received cystectomy, chemotherapy, and radiotherapy were associated with better OS ( $P<0.001, P<0.001$, and $P=0.016$, respectively) and CSS $(P<0.001, P<0.001$, and $P=0.003$, respectively; Figure $4 \mathrm{~A}-\mathrm{F})$. Cystectomy+chemotherapy+radiotherapy (CCR) patients had the best long-term OS and CSS, who received multiple treatment options (Figure 5A and B; Table 3). Table 2 represents the results of multivariate survival analysis using the Cox proportional hazard model. After adjusting for demographic, clinical, and treatment-related factors, the independent factors associated with CSS identified were age, histology, N stage, tumor size (centimeters), SEER stage, radiotherapy, chemotherapy, and cancer-directed surgery; all $P<0.05$.

\section{Differences between groups}

SCNEC and LCNEC of the bladder affect patients older than 60 years with a male predominance. Of patients with SCNEC, $81.8 \%$ of patients were older than 60 years and $75.3 \%$ were males. Of patients with LCNEC, $91.4 \%$ of patients were older than 60 years and $68.6 \%$ were males. On the contrary, $50 \%$ of patients with carcinoid tumor were not older than 60 years and $81.2 \%$ of patients with PGL/ PHEO were not older than 60 years. In the case of clear pathological grade, SCNEC and LCNEC cancers are more likely to be poorly differentiated or undifferentiated. The unclear TNM stage of carcinoid tumor and PGL/PHEO in this list is a limitation of this study. In SEER stage, $80 \%$ of carcinoids are at localized stage. However, the majority of small cells, large cells, and PGL/PHEO are at regional stage, 394 (60.8\%), 26 (74.3\%), 9 (56.2\%), respectively (Table 1). Interestingly, patients with carcinoids and PGL/ PHEO rarely received radiotherapy and chemotherapy, but the survival rates in carcinoids and PGL/PHEO patients were significantly higher than those in SCNEC and LCNEC 
Table I Characteristics of 910 patients with primary bladder neuroendocrine carcinomas

\begin{tabular}{|c|c|c|c|c|c|c|}
\hline Characteristics & $\begin{array}{l}\text { Total } \\
\text { patients, } \\
\text { n (\%) }\end{array}$ & $\begin{array}{l}\text { Small cell } \\
\text { neuroendocrine } \\
\text { carcinoma }\end{array}$ & $\begin{array}{l}\text { Large cell } \\
\text { neuroendocrine } \\
\text { carcinoma }\end{array}$ & $\begin{array}{l}\text { Carcinoid } \\
\text { tumor (well- } \\
\text { differentiated } \\
\text { neuroendocrine } \\
\text { tumor) } \\
\end{array}$ & $\begin{array}{l}\text { Paragangliomal } \\
\text { pheochromo- } \\
\text { cytoma }\end{array}$ & $\begin{array}{l}\text { Neuroendo- } \\
\text { crine } \\
\text { carcinoma, } \\
\text { NOS }\end{array}$ \\
\hline \multicolumn{7}{|l|}{ Age at diagnosis (years) } \\
\hline$\leq 60$ & $181(19.9)$ & $118(18.2)$ & $3(8.6)$ & $5(50.0)$ & $13(81.2)$ & $42(20.9)$ \\
\hline $6 I-70$ & $234(25.7)$ & $170(26.2)$ & II (3I.4) & $0(0.0)$ & $\mathrm{I}(6.2)$ & $52(25.9)$ \\
\hline $7 I-80$ & $278(30.5)$ & $189(29.2)$ & $15(42.9)$ & $3(30.0)$ & $\mathrm{I}(6.2)$ & $70(34.8)$ \\
\hline$>80$ & $217(23.8)$ & $171(26.4)$ & $6(17.1)$ & $2(20.0)$ & $\mathrm{I}(6.2)$ & $37(18.4)$ \\
\hline \multicolumn{7}{|l|}{ Race } \\
\hline White & 807 (88.7) & $589(90.9)$ & $29(82.9)$ & $7(70.0)$ & $8(50.0)$ & $174(86.6)$ \\
\hline Black & $59(6.5)$ & $32(4.9)$ & I (2.9) & $\mathrm{I}(10.0)$ & $6(37.5)$ & $19(9.5)$ \\
\hline Others & $44(4.8)$ & $27(4.2)$ & $5(14.3)$ & $2(20.0)$ & $2(12.5)$ & $8(4.0)$ \\
\hline \multicolumn{7}{|l|}{ Gender } \\
\hline Male & $675(74.2)$ & $488(75.3)$ & $24(68.6)$ & $7(70.0)$ & $10(62.5)$ & I46 (72.6) \\
\hline Female & $235(25.8)$ & $160(24.7)$ & II (3I.4) & $3(30.0)$ & $6(37.5)$ & $55(27.4)$ \\
\hline \multicolumn{7}{|l|}{ Marital status } \\
\hline Married & $527(57.9)$ & $371(57.3)$ & $22(62.9)$ & $8(80.0)$ & $10(62.5)$ & $116(57.7)$ \\
\hline Unmarried & $348(38.2)$ & $249(38.4)$ & $12(34.3)$ & $\mathrm{I}(10.0)$ & $6(37.5)$ & $80(39.8)$ \\
\hline Unknown & $35(3.8)$ & $28(4.3)$ & $\mathrm{I}(2.9)$ & $\mathrm{I}(\mathrm{I} 0.0)$ & $0(0.0)$ & $5(2.5)$ \\
\hline \multicolumn{7}{|l|}{ Grade } \\
\hline Well/moderately differentiated & $6(0.7)$ & $\mathrm{I}(0.2)$ & $0(0.0)$ & $2(20.0)$ & $\mathrm{I}(6.2)$ & $2(1.0)$ \\
\hline Poorly differentiated & $283(3 \mathrm{I} . \mathrm{I})$ & $176(27.2)$ & $14(40.0)$ & $0(0.0)$ & $0(0.0)$ & $93(46.3)$ \\
\hline Undifferentiated; anaplastic & $336(36.9)$ & $24 I(37.2)$ & $15(42.9)$ & $0(0.0)$ & $0(0.0)$ & $80(39.8)$ \\
\hline Unknown & $285(3 \mid .3)$ & $230(35.5)$ & $6(17.1)$ & $8(80.0)$ & $15(93.8)$ & $26(12.9)$ \\
\hline \multicolumn{7}{|l|}{ AJCC stage } \\
\hline$<T 2^{\mathrm{a}}$ & $131(14.4)$ & $95(14.7)$ & $3(8.6)$ & $0(0.0)$ & $0(0.0)$ & $33(16.4)$ \\
\hline$\geq T 2^{\mathrm{b}}$ & $694(76.3)$ & $508(78.4)$ & $31(88.6)$ & $0(0.0)$ & $0(0.0)$ & $155(77.1)$ \\
\hline Unknown & $85(9.3)$ & $45(6.9)$ & I (2.9) & $10(100.0)$ & $16(100.0)$ & $13(6.5)$ \\
\hline \multicolumn{7}{|l|}{ N stage } \\
\hline Node - negative & 649 (7I.3) & $474(73.1)$ & $29(82.9)$ & $0(0.0)$ & $0(0.0)$ & I $46(72.6)$ \\
\hline Node - positive & $168(18.5)$ & $123(19.0)$ & $5(14.3)$ & $0(0.0)$ & $0(0.0)$ & $40(19.9)$ \\
\hline Unknown & $93(10.2)$ & $5 I(7.9)$ & $\mathrm{I}(2.9)$ & $10(100.0)$ & $16(100.0)$ & $15(7.5)$ \\
\hline \multicolumn{7}{|l|}{ M stage } \\
\hline MO & 647 (7I.I) & $473(73.0)$ & $30(85.7)$ & $0(0.0)$ & $0(0.0)$ & I44 (7I.6) \\
\hline $\mathrm{MI}$ & $214(23.5)$ & $159(24.5)$ & $5(14.3)$ & $0(0.0)$ & $0(0.0)$ & $50(24.9)$ \\
\hline Unknown & $49(5.4)$ & $16(2.5)$ & $0(0.0)$ & $10(100)$ & $16(100.0)$ & $7(3.5)$ \\
\hline \multicolumn{7}{|l|}{ Tumor size $(\mathrm{cm})$} \\
\hline$\leq 2$ & $66(7.3)$ & $44(6.8)$ & $2(5.7)$ & $4(40.0)$ & $5(3 \mid .2)$ & II (5.5) \\
\hline $2-5$ & $298(32.7)$ & $222(34.3)$ & $13(37.1)$ & $\mathrm{I}(10.0)$ & $4(25.0)$ & $58(28.9)$ \\
\hline$>5$ & $200(22.0)$ & $143(22.1)$ & $7(20.0)$ & $0(0.0)$ & $3(18.8)$ & $47(23.4)$ \\
\hline Unknown & $346(38.0)$ & $239(36.9)$ & $13(37.1)$ & $5(50.0)$ & $4(25.0)$ & $85(42.3)$ \\
\hline \multicolumn{7}{|l|}{ Tumor location } \\
\hline Trigone & $50(5.5)$ & $31(4.8)$ & $2(5.7)$ & $2(20.0)$ & $0(0.0)$ & I5 (7.5) \\
\hline Dome & $63(6.9)$ & $42(6.5)$ & 4 (II.4) & $\mathrm{I}(10.0)$ & $2(12.5)$ & $14(7.0)$ \\
\hline Lateral wall & $170(18.7)$ & $125(19.3)$ & $7(20.0)$ & $\mathrm{I}(10.0)$ & $2(12.5)$ & $35(17.4)$ \\
\hline Anterior wall & $49(5.4)$ & $33(5.1)$ & $0(0.0)$ & $0(0.0)$ & $\mathrm{I}(6.3)$ & $15(7.5)$ \\
\hline Posterior wall & \begin{tabular}{|l|}
$81(8.9)$ \\
\end{tabular} & $59(9.1)$ & 4 (II.4) & $\mathrm{I}(10.0)$ & $3(18.8)$ & I4 (7.0) \\
\hline Bladder neck & $20(2.2)$ & $12(1.9)$ & $\mathrm{I}(2.9)$ & $2(20.0)$ & $2(12.5)$ & $3(1.5)$ \\
\hline Ureteric orifice & $15(1.6)$ & II (I.7) & $0(0.0)$ & $0(0.0)$ & $0(0.0)$ & $4(2.0)$ \\
\hline Urachus & $2(0.2)$ & $\mathrm{I}(0.2)$ & $0(0.0)$ & $0(0.0)$ & $0(0.0)$ & $\mathrm{I}(0.5)$ \\
\hline Overlapping subsites & $145(15.9)$ & $105(16.2)$ & $7(20.0)$ & $0(0.0)$ & $0(0.0)$ & $33(16.4)$ \\
\hline Bladder, NOS & $315(34.6)$ & $229(35.3)$ & $10(28.6)$ & $3(30.0)$ & $6(37.5)$ & $67(33.3)$ \\
\hline \multicolumn{7}{|l|}{ SEER stage } \\
\hline Localized & $109(12.0)$ & $68(10.5)$ & $3(8.6)$ & $8(80.0)$ & $3(18.8)$ & $27(13.4)$ \\
\hline Regional & $542(59.6)$ & $394(60.8)$ & $26(74.3)$ & $0(0.0)$ & $9(56.2)$ & $113(56.2)$ \\
\hline Distant & $228(25.1)$ & I7I (26.4) & $5(14.3)$ & $0(0.0)$ & I (6.2) & $5 I(25.4)$ \\
\hline Unstaged & $31(3.4)$ & $15(2.3)$ & $\mathrm{I}(2.9)$ & $2(20.0)$ & $3(18.8)$ & $10(5.0)$ \\
\hline
\end{tabular}


Table I (Continued)

\begin{tabular}{|c|c|c|c|c|c|c|}
\hline Characteristics & $\begin{array}{l}\text { Total } \\
\text { patients, } \\
\text { n (\%) }\end{array}$ & $\begin{array}{l}\text { Small cell } \\
\text { neuroendocrine } \\
\text { carcinoma }\end{array}$ & $\begin{array}{l}\text { Large cell } \\
\text { neuroendocrine } \\
\text { carcinoma }\end{array}$ & $\begin{array}{l}\text { Carcinoid } \\
\text { tumor (well- } \\
\text { differentiated } \\
\text { neuroendocrine } \\
\text { tumor) }\end{array}$ & $\begin{array}{l}\text { Paraganglioma/ } \\
\text { pheochromo- } \\
\text { cytoma }\end{array}$ & $\begin{array}{l}\text { Neuroendo- } \\
\text { crine } \\
\text { carcinoma, } \\
\text { NOS }\end{array}$ \\
\hline \multicolumn{7}{|l|}{ Radiotherapy } \\
\hline Yes & $227(24.9)$ & $175(27.0)$ & $8(22.9)$ & $0(0.0)$ & $0(0.0)$ & $44(21.9)$ \\
\hline None/unknown & $683(75.1)$ & $473(73.0)$ & $27(77.1)$ & $10(100.0)$ & $16(100.0)$ & $157(78.1)$ \\
\hline \multicolumn{7}{|l|}{ Chemotherapy } \\
\hline Yes & $521(57.3)$ & $396(6 I . I)$ & $21(60.0)$ & $0(0.0)$ & $I(6.2)$ & $103(5 \mid .2)$ \\
\hline None/unknown & $389(42.7)$ & $252(38.9)$ & $14(40.0)$ & $10(100.0)$ & $15(93.8)$ & $98(48.8)$ \\
\hline \multicolumn{7}{|c|}{ Cancer-directed surgery } \\
\hline None & $74(8.1)$ & $57(8.8)$ & $\mathrm{I}(2.9)$ & $\mathrm{I}(10.0)$ & $2(12.5)$ & $13(6.5)$ \\
\hline Ablation $^{c}$ & $586(64.4)$ & $417(64.4)$ & $25(71.4)$ & $8(80.0)$ & $5(3 \mid .2)$ & $13 \mid(65.2)$ \\
\hline Cystectomy $^{d}$ & $245(26.9)$ & $170(26.2)$ & $9(25.7)$ & $\mathrm{I}(10.0)$ & $9(56.3)$ & $56(27.9)$ \\
\hline Surgery, NOS & $5(0.5)$ & $4(0.6)$ & $0(0.0)$ & $0(0.0)$ & $0(0.0)$ & $\mathrm{I}(0.5)$ \\
\hline
\end{tabular}

Notes: aNMIBC. bMIBC. cAblation/resection. dPartial/radical cystectomy.

Abbreviations: AJCC, American Joint Committee on Cancer; MIBC, muscle-invasive bladder cancer; NMIBC, non-muscle-invasive bladder cancer; NOS, not otherwise specified; SEER, Surveillance, Epidemiology, and End Results.

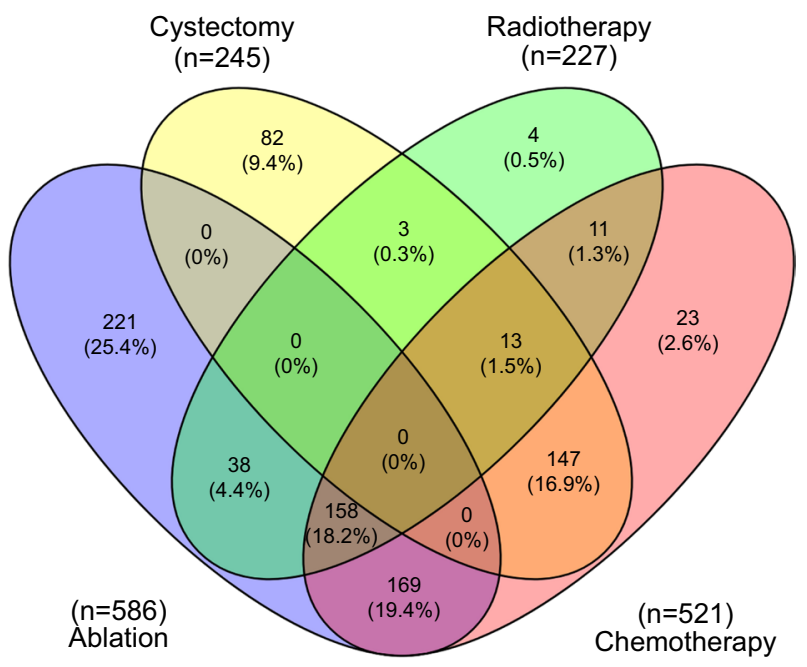

Figure I Venn diagram of the main therapy of bladder neuroendocrine carcinomas.

patients. Of course, the pathological grade will be an important factor. As we know, SCNEC and LCNEC are mostly poorly differentiated or undifferentiated.

\section{Discussion}

Neuroendocrine tumor is a rare type of tumor of the urinary bladder that accounts for a small percentage of urinary bladder neoplasms. The clinical significance and biologic behavior of primary BNEC need to be further characterized by performing more extensive studies with long-term follow-up. This study took the advantage of a multitude of data collected by the SEER Program to examine the largest series of BNEC reported to date.
The urinary bladder is the most common site for extrapulmonary small cell carcinoma, and small cell carcinoma accounts for less than $1 \%$ of all the primary BCas. ${ }^{5,9}$ The most vulnerable group of people for BNEC tends to be older men. ${ }^{4,10,11}$ PGL, an extra-adrenal PHEO, accounts for $18 \%$ of PHEOs, with $10 \%$ of the cases occurring in the bladder. ${ }^{12}$ Primary PGL of the bladder is very rare and accounts for less than $0.06 \%$ of all bladder tumors and $<1 \%$ of all PGLs. PGLs of the urinary bladder can present at any age (range, 11-84 years) with a mean age of 45 years. ${ }^{13}$ In contrast with SCNEC/LCNEC, only $18.2 \%$ of patients with PGL/PHEO were older than 60 years.

There are a number of theories for the cell of origin for SCNEC/LCNEC. The molecular genetic evidence of common clonal origin of coexisting small cell carcinoma of the urinary bladder suggests that the cell of origin was multipotential, undifferentiated cell, or stem cell. ${ }^{14}$ Similar hypothesis of large cell carcinoma common to the other neuroendocrine tumors of the urinary bladder including multipotent stem cells, originating from the submucosa neuroendocrine cells or urinary tract epithelial metaplasia. ${ }^{15}$ In the 648 small cell carcinoma cases, $37.2 \%$ were undifferentiated/anaplastic. At the same time, in the 35 large cell carcinoma cases, $42.9 \%$ were undifferentiated/anaplastic. Therefore, the patients tend to undergo surgery once the cancer is diagnosed. Percentage of patients undergoing surgery for SCNEC and LCNEC were $91.2 \%$ and $97.1 \%$, respectively.

Currently, the National Comprehensive Cancer Network $(\mathrm{NCCN})$ guidelines state that patients with small cell 
A

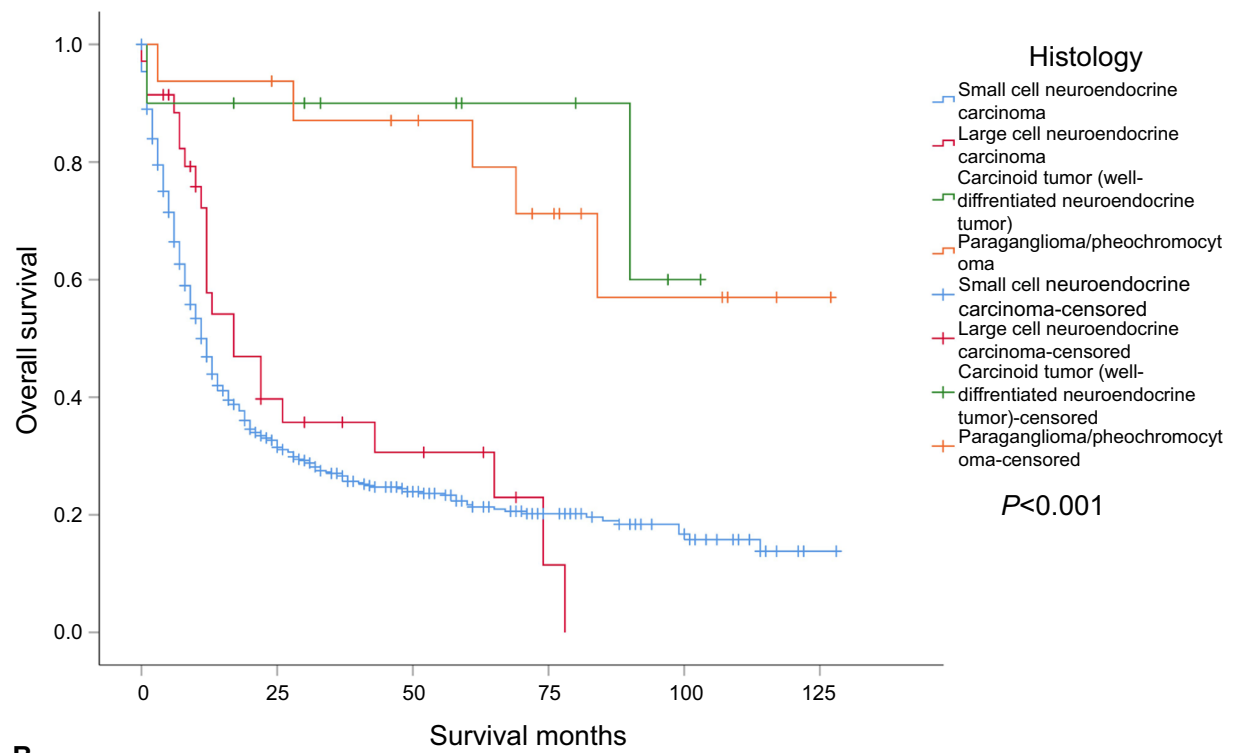

B

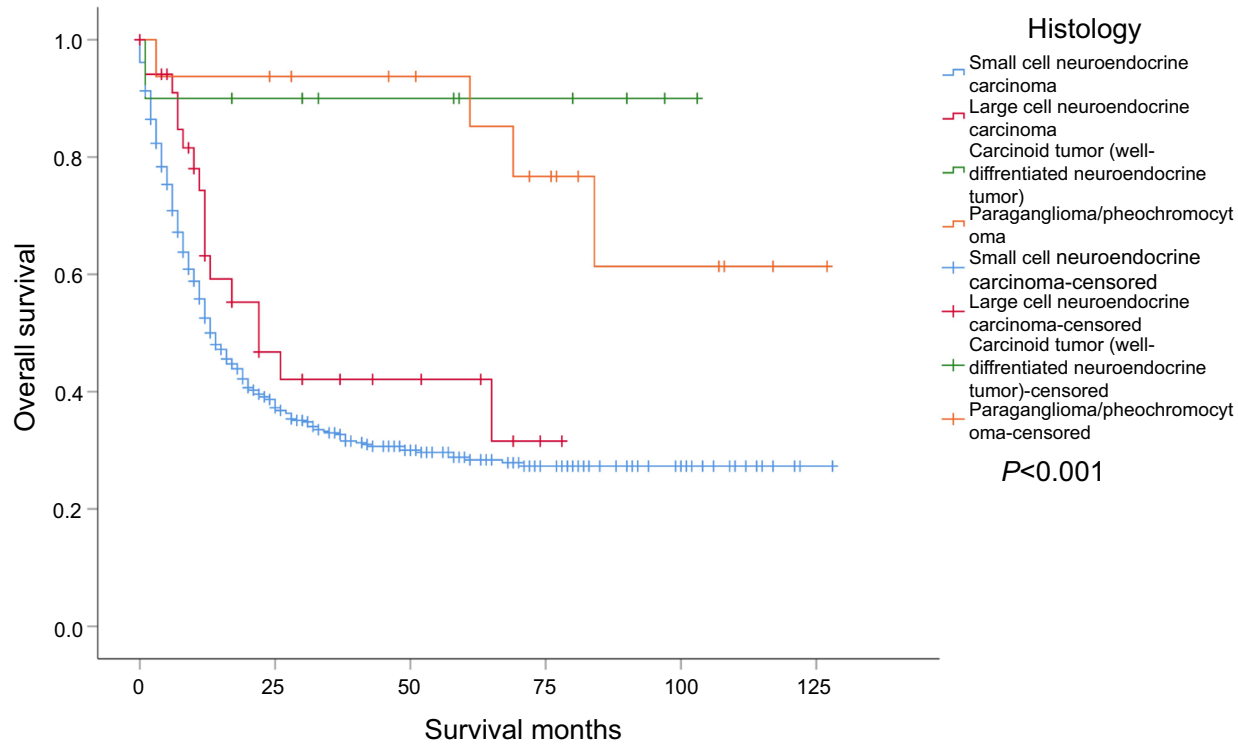

Figure 2 Kaplan-Meier curves of overall survival and cancer-specific survival according to the histology of bladder neuroendocrine carcinomas $(\mathbf{A}, \mathbf{B})$; all $P<0.05$.

carcinoma of the bladder are best treated with neoadjuvant chemotherapy followed by radiation or cystectomy. ${ }^{16}$ Chemotherapy regimens have been extrapolated from the pulmonary counterpart and consist of cisplatin, gemcitabine, ifosfamide, and paclitaxel as first-line agents for patients presenting with extensive disease.${ }^{17} \mathrm{~A}$ combination of radical surgery and platinum-based neoadjuvant chemotherapy has been shown to improve survival. ${ }^{18}$ According to the National Cancer Database data, radical cystectomy plus chemotherapy and chemoradiation therapy are associated with better OS compared to monotherapy. ${ }^{19}$ Another study found that chemotherapy improved patient survival in localized stage, regional stage, and distant stage disease in conjunction with transurethral resection; radiation positively affects the survival after transurethral resection of bladder tumor (TURBT) in regional stage disease. ${ }^{20}$

Due to the scarcity of reported cases, there is no standard treatment; however, multimodal therapy with surgery and chemotherapy has been used. ${ }^{21}$ Similar to SCNEC of the urinary bladder, the diagnosis and treatment of LCNEC of the urinary bladder is similar for the pulmonary counterpart. ${ }^{18} \mathrm{~A}$ report described a difference in five patients with LCNEC treated with adjuvant chemotherapy vs surgery alone (116vs 2 29 months, respectively). ${ }^{22}$ A total of 17 cases have found that radical cystectomy with lymphadenectomy combined with chemotherapy can sometime reduce local and distant recurrence and improve the survival of LCNEC of the bladder. ${ }^{23}$ 

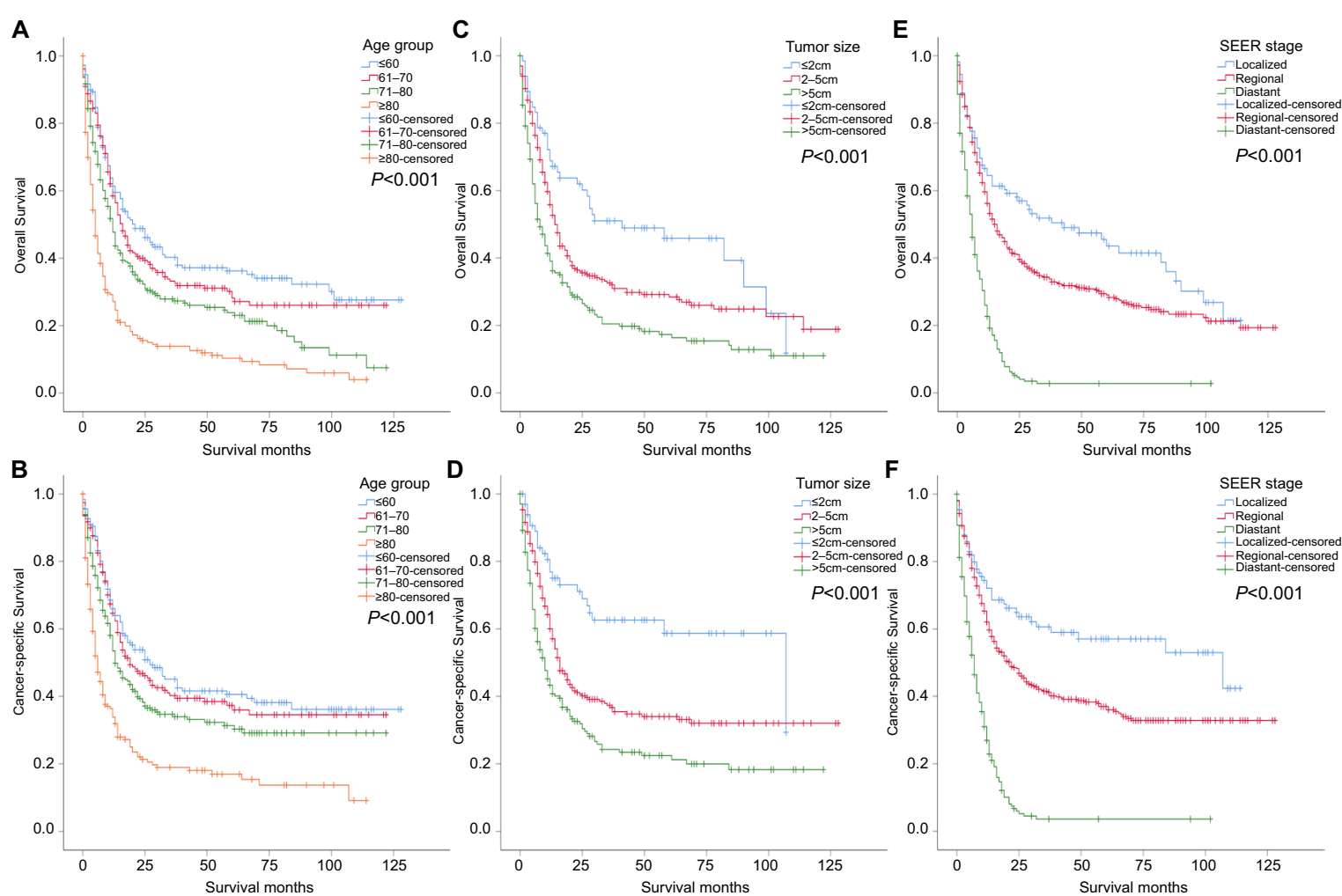

Figure 3 Kaplan-Meier curves of overall survival and cancer-specific survival according to age (A, B), tumor size (C, D), and SEER stage (E, F) of bladder neuroendocrine carcinomas; all $P<0.05$.

Abbreviation: SEER, Surveillance, Epidemiology, and End Results.
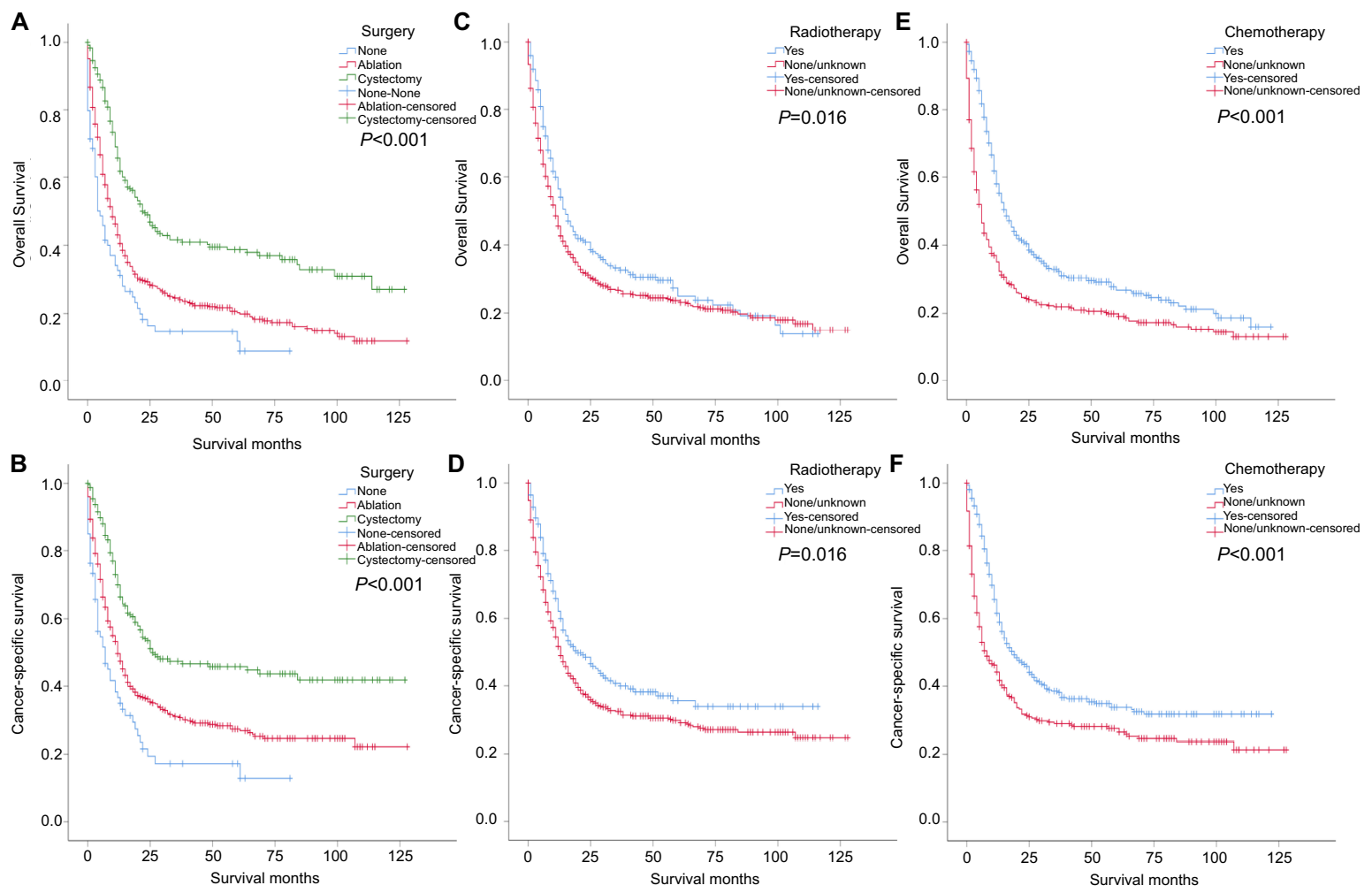

Figure 4 Kaplan-Meier curves of overall survival and cancer-specific survival according to surgery (A, B), radiotherapy (C, D), and chemotherapy (E, F) of bladder neuroendocrine carcinomas; all $P<0.05$. 
A
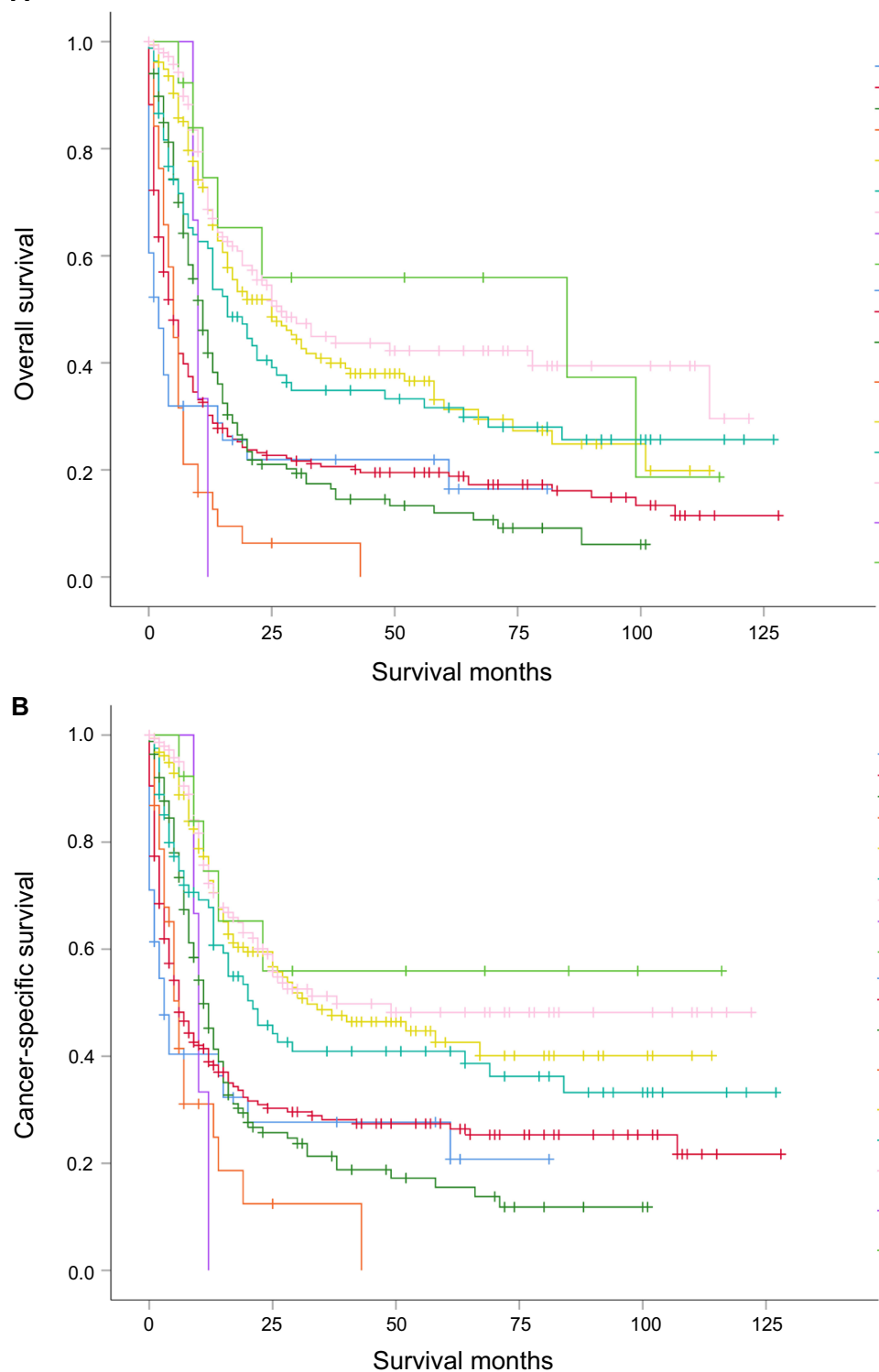

Therapy

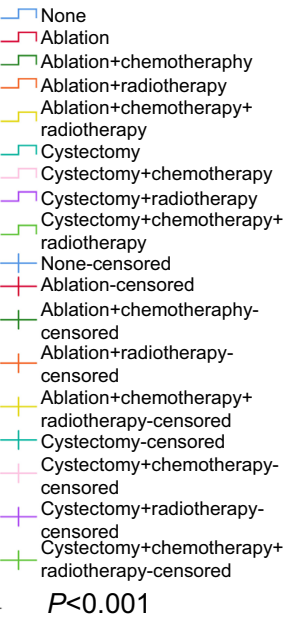

$P<0.001$

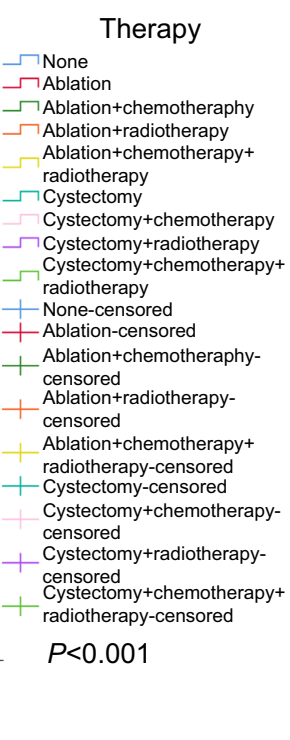

Figure 5 Kaplan-Meier curves of overall survival and cancer-specific survival according to multiple treatment methods (A, B) of bladder neuroendocrine carcinomas; all $P<0.05$.

The prognosis is excellent for typical well-differentiated neuroendocrine tumors limited to the lamina propria. Previous reports suggest that the pure well-differentiated neuroendocrine tumors of the bladder appear to have excellent prognosis, and the number of cases is small with limited follow-up periods..$^{24,25}$ Our data and long-term follow-up are consistent with their views. The long-term survival rate of carcinoids and PGL/PHEO is significantly higher than that of SCNEC/LCNEC (Figure 2). The treatment for localized disease is similar to the treatment of carcinoids at other body sites and primarily involves surgical resection with clinical follow-up. ${ }^{26}$ In case of 10 carcinoids, $80 \%$ were at localized stage; all patients received only local treatment; and none of them received adjuvant radiotherapy or chemotherapy (Table 1).

The majority of bladder PGLs are hormonally active and can present with clinical symptoms secondary to catecholamine release with micturition attacks such as headache, hypertension, palpitations, diaphoresis, and blurred vision before or during voiding. ${ }^{27,28}$ Therefore, bladder PGL is easier to diagnose than other three types of tumors. For treatment, most scholars suggest combining radical bladder cystectomy and chemotherapy to improve clinical effectiveness. ${ }^{27,29}$ Due to the lack of high-quality data allowing organizational guidelines to publish treatment guidelines, there is no standard treatment. Traditional chemotherapy with cyclophosphamide, 
Table 2 Multivariate Cox regression analysis of prognostic factors influencing survival outcomes in bladder neuroendocrine carcinomas

\begin{tabular}{|c|c|c|c|c|}
\hline \multirow[t]{2}{*}{ Features } & \multicolumn{2}{|l|}{ Overall survival } & \multicolumn{2}{|c|}{ Cancer-specific survival } \\
\hline & HR (95\% Cl) & $P$-value & HR (95\% Cl) & $P$-value \\
\hline \multicolumn{5}{|l|}{ Age at diagnosis (years) } \\
\hline$\leq 60$ & 1.000 (reference) & & 1.000 (reference) & \\
\hline $6 I-70$ & $1.068(0.826-1.382)$ & 0.616 & $\mathrm{I} .02 \mathrm{I}(0.772-\mathrm{I} .35 \mathrm{I})$ & 0.883 \\
\hline $7 I-80$ & $1.528(1.197-1.950)$ & 0.001 & $1.413(1.083-1.842)$ & 0.011 \\
\hline$>80$ & $1.908(1.465-2.486)$ & $<0.001$ & $1.873(1.403-2.500)$ & $<0.001$ \\
\hline \multicolumn{5}{|l|}{ Race } \\
\hline White & $\mathrm{I} .000$ (reference) & & 1.000 (reference) & \\
\hline Black & $1.089(0.778-1.524)$ & 0.619 & $1.085(0.752-1.566)$ & 0.662 \\
\hline Others & $0.774(0.494-1.214)$ & 0.265 & $0.669(0.398-1.124)$ & 0.129 \\
\hline \multicolumn{5}{|l|}{ Gender } \\
\hline Male & 1.000 (reference) & & 1.000 (reference) & \\
\hline Female & $0.84 \mathrm{I}(0.690-1.025)$ & 0.086 & $0.927(0.748-1.149)$ & 0.630 \\
\hline \multicolumn{5}{|l|}{ Marital status } \\
\hline Married & I.000 (reference) & & 1.000 (reference) & \\
\hline Unmarried & $1.225(1.026-1.464)$ & 0.025 & $1.113(0.914-1.356)$ & 0.286 \\
\hline \multicolumn{5}{|l|}{ Grade } \\
\hline Well/moderately differentiated & $\mathrm{I} .000$ (reference) & & 1.000 (reference) & \\
\hline Poorly differentiated & $0.848(0.211-3.409)$ & 0.816 & $4.048(0.292-56.131)$ & 0.297 \\
\hline Undifferentiated; anaplastic & $0.870(0.217-3.487)$ & 0.844 & $3.950(0.283-55.148)$ & 0.307 \\
\hline \multicolumn{5}{|l|}{ Histology } \\
\hline Small cell carcinoma & I.000 (reference) & & 1.000 (reference) & \\
\hline Large cell neuroendocrine carcinoma & $0.723(0.470-1.113)$ & 0.140 & $0.649(0.395-1.068)$ & 0.089 \\
\hline Carcinoid tumor & $0.096(0.019-0.478)$ & 0.004 & $0.073(0.009-0.617)$ & 0.016 \\
\hline Paraganglioma/pheochromocytoma & $0.115(0.038-0.346)$ & $<0.001$ & $0.108(0.033-0.358)$ & $<0.001$ \\
\hline \multicolumn{5}{|l|}{ AJCC stage } \\
\hline$<\mathrm{T}^{\mathrm{a}}$ & 1.000 (reference) & & 1.000 (reference) & \\
\hline$\geq \mathrm{T}^{\mathrm{b}}$ & $0.873(0.568-1.343)$ & 0.537 & $0.808(0.5|4-| .27 \mid)$ & 0.356 \\
\hline \multicolumn{5}{|l|}{ N stage } \\
\hline Node - negative & 1.000 (reference) & & 1.000 (reference) & \\
\hline Node - positive & $1.457(1.176-1.806)$ & 0.001 & $1.585(1.260-1.995)$ & $<0.001$ \\
\hline \multicolumn{5}{|l|}{ M stage } \\
\hline MO & $\mathrm{I} .000$ (reference) & & 1.000 (reference) & \\
\hline $\mathrm{MI}$ & $0.803(0.437-1.475)$ & 0.480 & $0.979(0.49 I-I .95 I)$ & 0.952 \\
\hline \multicolumn{5}{|l|}{ Tumor size $(\mathrm{cm})$} \\
\hline$\leq 2$ & 1.000 (reference) & & 1.000 (reference) & \\
\hline $2-5$ & $1.187(0.818-1.723)$ & 0.367 & $\mathrm{I} .5 \mathrm{I} 0(0.96 \mathrm{I}-2.372)$ & 0.074 \\
\hline$>5$ & $1.650(1.126-2.418)$ & 0.010 & $2.082(1.3 \mid 3-3.30 I)$ & 0.002 \\
\hline \multicolumn{5}{|l|}{ Tumor location } \\
\hline Trigone & I.000 (reference) & & 1.000 (reference) & \\
\hline Dome & $1.162(0.726-1.862)$ & 0.531 & $0.986(0.573-1.694)$ & 0.958 \\
\hline Lateral wall & $1.388(0.934-2.062)$ & 0.105 & $\mathrm{I} .428(0.92 \mathrm{I}-2.2 \mathrm{I} 2)$ & 0.111 \\
\hline Anterior wall & $1.191(0.729-1.945)$ & 0.485 & $1.366(0.807-2.3 \mid 2)$ & 0.246 \\
\hline Posterior wall & $1.230(0.789-1.915)$ & 0.361 & $1.269(0.776-2.076)$ & 0.342 \\
\hline Bladder neck & $1.465(0.725-2.959)$ & 0.288 & $1.429(0.656-3.1 \mathrm{II})$ & 0.369 \\
\hline Ureteric orifice & $0.488(0.200-1.190)$ & 0.115 & $0.546(0.218-1.369)$ & 0.197 \\
\hline Urachus & $0.469(0.046-4.75 \mathrm{I})$ & 0.522 & $2.219(0.158-31.191)$ & 0.555 \\
\hline Overlapping subsites & $1.488(0.994-2.227)$ & 0.054 & $1.372(0.878-2.145)$ & 0.165 \\
\hline \multicolumn{5}{|l|}{ SEER stage } \\
\hline Localized & 1.000 (reference) & & I.000 (reference) & \\
\hline Regional & $1.706(1.021-2.852)$ & 0.041 & $1.980(1.129-3.470)$ & 0.017 \\
\hline Distant & $4.564(2.070-10.059)$ & $<0.001$ & $4.875(2.017-1 \mathrm{I} .786)$ & $<0.001$ \\
\hline \multicolumn{5}{|l|}{ Radiotherapy } \\
\hline Yes & 1.000 (reference) & & 1.000 (reference) & \\
\hline None/unknown & $1.398(1.136-1.721)$ & 0.002 & 1.521 (1.207-1.918) & $<0.001$ \\
\hline
\end{tabular}


Table 2 (Continued)

\begin{tabular}{|c|c|c|c|c|}
\hline \multirow[t]{2}{*}{ Features } & \multicolumn{2}{|l|}{ Overall survival } & \multicolumn{2}{|c|}{ Cancer-specific survival } \\
\hline & HR $(95 \% \mathrm{Cl})$ & $P$-value & HR (95\% Cl) & $P$-value \\
\hline \multicolumn{5}{|l|}{ Chemotherapy } \\
\hline Yes & 1.000 (reference) & & 1.000 (reference) & \\
\hline None/unknown & $1.945(1.612-2.345)$ & $<0.001$ & $1.916(1.558-2.356)$ & $<0.001$ \\
\hline \multicolumn{5}{|c|}{ Cancer-directed surgery } \\
\hline None & I.000 (reference) & & 1.000 (reference) & \\
\hline Ablation & $0.983(0.7|6-| .35 \mid)$ & 0.917 & $0.97 \mid(0.689-\mid .367)$ & 0.864 \\
\hline Cystectomy & $0.522(0.355-0.768)$ & 0.001 & $0.538(0.354-0.819)$ & 0.004 \\
\hline
\end{tabular}

Notes: ${ }^{a}$ NMIBC. ${ }^{b}$ MIBC.

Abbreviations: AJCC, American Joint Committee on Cancer; MIBC, muscle-invasive bladder cancer; NMIBC, non-muscle-invasive bladder cancer; SEER, Surveillance, Epidemiology, and End Results.

Table 3 I-, 3-, and 5-years overall survival and cancer-specific survival of patients with BNEC according to therapy

\begin{tabular}{|c|c|c|c|c|c|c|c|c|}
\hline \multirow[t]{2}{*}{ Therapy } & \multicolumn{3}{|c|}{ Overall survival rate (\%) } & \multirow{2}{*}{$\begin{array}{l}\text { Median time } \\
\text { (months) }\end{array}$} & \multicolumn{3}{|c|}{ Cancer-specific survival rate (\%) } & \multirow{2}{*}{$\begin{array}{l}\text { Median time } \\
\text { (months) }\end{array}$} \\
\hline & I year & 3 years & 5 years & & I year & 3 years & 5 years & \\
\hline None & 22 & 22 & 14 & 8.76 & 28 & 28 & 19 & 10.20 \\
\hline Ablation & 24 & 20 & 17 & 8.96 & 31 & 28 & 26 & 10.32 \\
\hline$A C$ & 21 & 14 & 12 & 11.26 & 25 & 19 & 12 & 12.46 \\
\hline AR & 6 & 0 & & 7.03 & $\mathrm{II}$ & 0 & & 8.38 \\
\hline ACR & 51 & 37 & 29 & 25.42 & 59 & 46 & 40 & 33.77 \\
\hline Cystectomy & $4 \mathrm{I}$ & 35 & 25 & 18.88 & 46 & $4 \mathrm{I}$ & 36 & 21.82 \\
\hline $\mathrm{CC}$ & 56 & 44 & 31 & 30.98 & 61 & 50 & 48 & 46.23 \\
\hline CCR & 56 & 56 & 56 & 88.00 & 56 & 56 & 56 & 108.00 \\
\hline
\end{tabular}

Note: Less than 30 patients were not included in the comparison, except CCR group.

Abbreviations: AC, ablation+chemotherapy; ACR, ablation+chemotherapy+radiotherapy; AR, ablation+radiotherapy; BNEC, bladder neuroendocrine carcinomas; CC, cystectomy+chemotherapy; CCR, cystectomy+chemotherapy+radiotherapy.

vincristine, and dacarbazine (CVD) has been used most extensively with PGL/PHEO and still remains one of the most effective treatments for widespread metastatic disease. ${ }^{30}$ In our study, $80 \%$ of PGL/PHEO were younger patients less than 60 years old, $56 \%$ were regional stage, and $18 \%$ were localized stage. Therefore, although only one patient received adjuvant chemotherapy after surgery, PGL/PHEO still had better OS and CSS.

Limitations of the study include the lack of central review of pathology reports. In addition, information regarding patients' comorbidities is not available in SEER database, all of which may influence survival in cancer patients. The chemotherapy in the SEER database was only described as yes, no, or unknown. Considering that the total number of patients received radiotherapy was small, we divided all patients who received radiotherapy into yes group and vice versa into no group. The SEER data lack information of the neoadjuvant chemoradiation therapy methods. In spite of this, we still found that patients who received radiotherapy or chemotherapy have a better long-term survival than patients who received same surgery without radiotherapy or chemotherapy among multiple treatments. Therefore, we suggest that people can research the specific chemotherapy or radiotherapy regimen to have the best therapeutic effect on bladder neuroendocrine tumors in future studies. Finally, sample size in this study may still not be enough to fully describe the factors that affect the incidence, treatment choice, and survival of this rare tumor.

\section{Conclusion}

In BNEC, SCNEC has an absolute advantage in number. SCNEC/LCNEC tend to be older men. For treatment, all of ablation, cystectomy, radiotherapy, and chemotherapy are better than conservative treatment. However, whatever cystectomy and bladder sparing, chemotherapy should be a major component of treatment. But in this respect, more in-depth study is needed.

\section{Acknowledgment}

This study was supported by the National Natural Science Foundation of China (No. 81572702) and grants from the Postdoctoral Science Foundation of China (No. 2017M611755). 


\section{Disclosure}

The authors report no conflicts of interest in this work.

\section{References}

1. Siegel RL, Miller KD, Jemal A. Cancer Statistics, 2017. CA Cancer J Clin. 2017;67(1):7-30.

2. Humphrey PA, Moch H, Cubilla AL, Ulbright TM, Reuter VE. The 2016 WHO Classification of Tumours of the Urinary System and Male Genital Organs-Part B: Prostate and Bladder Tumours. Eur Urol. 2016;70(1):106-119.

3. Kouba E, Cheng L. Neuroendocrine Tumors of the Urinary Bladder According to the 2016 World Health Organization Classification: Molecular and Clinical Characteristics. Endocr Pathol. 2016;27(3): 188-199.

4. Radović N, Turner R, Bacalja J. Primary "Pure" Large Cell Neuroendocrine Carcinoma of the Urinary Bladder: A Case Report and Review of the Literature. Clin Genitourin Cancer. 2015;13(5):e375-e377.

5. Hou CP, Lin YH, Chen CL, Chang PL, Tsui KH. Clinical outcome of primary small cell carcinoma of the urinary bladder. Onco Targets Ther. 2013;6:1179-1185.

6. Henderson SJ, Kearns PJ, Tong CM, et al. Patients with urinary bladder paragangliomas: a compiled case series from a literature review for clinical management. Urology. 2015;85(4):e25-e29.

7. Chen YB, Epstein JI. Primary carcinoid tumors of the urinary bladder and prostatic urethra: a clinicopathologic study of 6 cases. Am J Surg Pathol. 2011;35(3):442-446.

8. Travis WD, Linnoila RI, Tsokos MG, et al. Neuroendocrine tumors of the lung with proposed criteria for large-cell neuroendocrine carcinoma. An ultrastructural, immunohistochemical, and flow cytometric study of 35 cases. Am J Surg Pathol. 1991;15(6):529-553.

9. Cheng L, Pan C-X, Yang XJ, et al. Small cell carcinoma of the urinary bladder: a clinicopathologic analysis of 64 patients. Cancer. 2004;101(5):957-962.

10. Eliyakin N, Postaci H, Baskin Y, Kozacioğlu Z. Small Cell Carcinoma of the Urinary Bladder: KIT and PDGFRA Gene Mutations. Rare Tumors. 2015;7(4):5982.

11. Shatagopam K, Kaimakliotis HZ, Cheng L, Koch MO. Genitourinary small cell malignancies: prostate and bladder. Future Oncol. 2015;11(3):479-488.

12. Scoazec JY, Couvelard A, Reseau T, Réseau TENpath. Classification of pancreatic neuroendocrine tumours: Changes made in the 2017 WHO classification of tumours of endocrine organs and perspectives for the future. Ann Pathol. 2017;37(6):444-456.

13. Priyadarshi V, Pal DK. Paraganglioma of urinary bladder. Urol Ann. 2015;7(3):402-404.

14. Cheng L, Jones TD, Mccarthy RP, et al. Molecular genetic evidence for a common clonal origin of urinary bladder small cell carcinoma and coexisting urothelial carcinoma. Am J Pathol. 2005;166(5): $1533-1539$.
15. Williamson SR, Zhang S, Yao JL, et al. ERG-TMPRSS2 rearrangement is shared by concurrent prostatic adenocarcinoma and prostatic small cell carcinoma and absent in small cell carcinoma of the urinary bladder: evidence supporting monoclonal origin. Mod Pathol. 2011;24(8):1120-1127.

16. Pasquier D, Barney B, Sundar S, et al. Small Cell Carcinoma of the Urinary Bladder: A Retrospective, Multicenter Rare Cancer Network Study of 107 Patients. Int J Radiat Oncol Biol Phys. 2015;92(4):904-910.

17. Kawahara T, Nishiyama H, Yamamoto S, Kamoto T, Ogawa O. Protocol consisting of cisplatin, etoposide and irinotecan induced complete pathological remission of primary small cell carcinoma of the bladder. Int J Urol. 2006;13(9):1251-1253.

18. Bhatt VR, Loberiza FR, Tandra P, Krishnamurthy J, Shrestha R, Wang J. Risk factors, therapy and survival outcomes of small cell and large cell neuroendocrine carcinoma of urinary bladder. Rare Tumors. 2014;6(1):5043.

19. Fischer-Valuck BW, Rao YJ, Henke LE, et al. Treatment Patterns and Survival Outcomes for Patients with Small Cell Carcinoma of the Bladder. Eur Urol Focus. 2017;S2405-4569(17):30205-5.

20. Koay EJ, Teh BS, Paulino AC, Butler EB. Treatment trends and outcomes of small-cell carcinoma of the bladder. Int J Radiat Oncol Biol Phys. 2012;83(1):64-70.

21. Sari A, Ermete M, Sadullahoğlu C, Bal K, Bolükbaşi A. Large cell neuroendocrine carcinoma of urinary bladder; case presentation. Turk Patoloji Derg. 2013;29(2):138-142.

22. Gupta S, Thompson RH, Boorjian SA, et al. High grade neuroendocrine carcinoma of the urinary bladder treated by radical cystectomy: a series of small cell, mixed neuroendocrine and large cell neuroendocrine carcinoma. Pathology. 2015;47(6):533-542.

23. Martín IJ, Vilar DG, Aguado JM, et al. Large cell neuroendocrine carcinoma of the urinary bladder. Bibliographic review. Arch Esp Urol. 2011;64(2):105-113.

24. Baydar DE, Tasar C. Carcinoid tumor in the urinary bladder: unreported features. Am J Surg Pathol. 2011;35(11):1754-1757.

25. Hofland J, Feelders RA, Brabander T, Franssen GJH, de Herder WW. Recent developments in the diagnosis and therapy of well-differentiated neuroendocrine tumours. Neth J Med. 2018;76(3):100-108.

26. Kunz PL. Carcinoid and neuroendocrine tumors: building on success. J Clin Oncol. 2015;33(16):1855-1863.

27. Martucci VL, Pacak K. Pheochromocytoma and paraganglioma: diagnosis, genetics, management, and treatment. Curr Probl Cancer. 2014;38(1):7-41.

28. Beilan JA, Lawton A, Hajdenberg J, Rosser CJ. Pheochromocytoma of the urinary bladder: a systematic review of the contemporary literature. BMC Urol. 2013;13(1):22.

29. Roman-Gonzalez A, Jimenez C. Malignant pheochromocytomaparaganglioma: pathogenesis, TNM staging, and current clinical trials. Curr Opin Endocrinol Diabetes Obes. 2017;24(3):174-183.

30. Jimenez C, Rohren E, Habra MA, et al. Current and future treatments for malignant pheochromocytoma and sympathetic paraganglioma. Curr Oncol Rep. 2013;15(4):356-371.
Cancer Management and Research

\section{Publish your work in this journal}

Cancer Management and Research is an international, peer-reviewed open access journal focusing on cancer research and the optimal use of preventative and integrated treatment interventions to achieve improved outcomes, enhanced survival and quality of life for the cancer patient. The manuscript management system is completely online and includes
Dovepress

a very quick and fair peer-review system, which is all easy to use. Visit $\mathrm{http}: / /$ www.dovepress.com/testimonials.php to read real quotes from published authors. 